\title{
Ten-year Audit of Kawasaki Disease in a District General Hospital
}

Michael Davison, Georgios Meridis and Eugen-Matthias Strehle*

Northumbria Healthcare NHS Foundation Trust and School of Medicine, Newcastle University, Newcastle upon Tyne, United Kingdom

\begin{abstract}
Background: This audit aimed to evaluate the cases Kawasaki disease (KD) seen in the pediatric department of a community hospital over a 10-year-period. In particular, length of time to diagnosis and variations in treatment were reviewed. Possible effects of these factors on patient outcome in the acute and chronic phase of KD were analyzed.

Methods: Data were obtained from the hospital information and coding departments. The following parameters were studied: demographic characteristics, presenting signs and symptoms, duration and peak of fever, hemoglobin and platelet count, coagulation times, C-reactive protein, urine dipstick analysis, length of hospital admission and cardiovascular abnormalities. The data were compared using standard computer software.

Results: Eleven patients were identified. Seven of them were male, and the mean age was 35 months. Mean length of hospital stay was 5 days. Mean time from admission to diagnosis was 4 days. All but one patient were given one course of immunoglobulin upon diagnosis. Two developed coronary artery aneurysms and were still receiving aspirin therapy at the time of the audit. Eight of the 11 patients were treated with antibiotics during their time in hospital, all prescribed to treat suspected infections. Once KD had been confirmed antibiotics were stopped.

Conclusion: A retrospective case note audit was performed which found that delay in diagnosis may be associated with cardiac complications. The data analyzed highlight the importance of early diagnosis and adequate treatment of KD. It is likely that new genetic tests will help clinicians achieve these goals in the near future.
\end{abstract}

Keywords: Kawasaki disease; Mucocutaneous lymph node syndrome; Bilateral conjunctivitis; Cervical lymphadenopathy

\section{Introduction}

Kawasaki disease $(\mathrm{KD})$ or mucocutaneous lymph node syndrome is a rare autoimmune vasculitis affecting small and medium sized arteries in young children characterized by a fever lasting longer than five days. The child may also have signs of bilateral conjunctivitis, cervical lymphadenopathy, a polymorphous rash, cracking of the lips and changes in the oral mucosa, and desquamation of the extremities [1]. Having 4 or 5 of these symptoms classes the child as having complete $\mathrm{KD}$; incomplete or atypical $\mathrm{KD}$ is characterized by a patient displaying 3 or fewer of these signs accompanying the fever at diagnosis. KD has been shown to be the most common cause of acquired heart disease in children, leading to coronary artery aneurysms [2]. Correct diagnosis is therefore important, though can be difficult as the onset is similar to that of an upper respiratory tract infection, as well as scarlet fever, measles or rubella $[1,2]$. If the diagnosis is uncertain, it may be confirmed by the appearance of coronary artery aneurysms on echocardiogram or angiography. Irritability is another common symptom in $\mathrm{KD}$, though is not part of the diagnostic criteria.

In the light of recent advances regarding genetic diagnostic techniques, which will be expanded on further in the discussion, the hospital's current diagnostic process and management of $\mathrm{KD}$ were assessed.

A 10-year-audit of KD was performed, and the findings were compared with current literature guidelines on the management. Length of time to diagnosis and variations in treatment were analyzed and their effects on the outcome for the patients in the acute and chronic phase of $\mathrm{KD}$ were reviewed.

\section{Methods}

The audit was approved by the local trust and the notes of patients with $\mathrm{KD}$ over the last 10 years were acquired. The review period was between February 2003 and November 2012. The notes were analyzed in detail and the following factors were reviewed: age at diagnosis, sex, ethnicity, weight, duration and peak of fever, C-reactive protein concentration, length of hospital stay, hemoglobin and platelet levels, coagulation times, urine dipstick results, erythrocyte sedimentation rate, treatment including immunoglobulin and aspirin use, presenting symptoms, complications focusing on any cardiac abnormalities and any other abnormal results. All results obtained from blood tests were cross-referenced with the patient computer database to ensure they were recorded accurately. The computer database also allowed any imaging of the patient such as X-rays, ultrasounds or echocardiograms to be viewed and recorded. The data was then transferred anonymously to a digital form and analyzed.

\section{Results}

During the 10-year period 11 patients were identified with KD. Seven of the 11 patients were male and the average age was 35 months. The youngest was only 4 months old while the oldest patient diagnosed was 62 months old.

All the patients were found to have a fever lasting between 7 and 28 days. The average length of time the child had a fever was 10 days. All but one of the 11 patients had a highest recorded temperature over 39 degrees centigrade $\left({ }^{\circ} \mathrm{C}\right)$. Nine of these 10 patients experienced spiking temperatures before specific treatment for KD in the hospital.

${ }^{*}$ Corresponding author: Eugen-Matthias Strehle, Northumbria Healthcare NHS Foundation Trust and School of Medicine, Newcastle University, Newcastle upon Tyne, United Kingdom, E-mail: strehle@doctors.org.uk

Received April 05, 2013; Accepted April 20, 2013; Published April 22, 2013

Citation: Davison M, Meridis G, Strehle EM (2013) Ten-year Audit of Kawasak Disease in a District General Hospital. Human Genet Embryol 3: 106. doi:10.4172/2161-0436.1000106

Copyright: @ 2013 Davison M, et al. This is an open-access article distributed under the terms of the Creative Commons Attribution License, which permits unrestricted use, distribution, and reproduction in any medium, provided the original author and source are credited. 
Three of the patients were diagnosed with incomplete KD, as they did not have 4 or more of the symptoms of diagnostic criteria. All 11 patients developed cervical lymphadenopathy and 10 of the 11 having conjunctivitis and a polymorphous rash. Changes to the lips and oral mucosa were seen in 7 of the 11, with changes to the extremities seen only in6, although this can be a late symptom of the disease.

High C-reactive protein levels (CRP), those greater than $5 \mathrm{mg} / \mathrm{l}$, were seen in 10 of the 11 patients. The only patient who had a normal CRP level did not have his level checked during the initial presentation. The only time he had it recorded was after discharge at an outpatient appointment, after the initial diagnosis was missed. The mean CRP level in the children was found to be $126 \mathrm{mg} / \mathrm{l}$.

Only 4 patients were found to have a hemoglobin level below11 g/ $\mathrm{dl}$, so qualified as slightly anemic [1]. The average hemoglobin level was $10.8 \mathrm{~g} / \mathrm{dl}$. A high platelet count, above $450 \times 10^{9} / 1$ was found in 5 of the patients, with a mean of $460 \times 10^{9} / 1$.

All but one of the patients were given a course of immunoglobulin upon diagnosis; the only exception being the child who was not diagnosed initially but later at an outpatient clinic. He was also the only child not to receive high dose aspirin as the clinicians thought it unnecessary as his symptoms had settled, although his fever lasted for 28 days. He was 1 of only 2 children to develop cardiac complications; three left coronary artery aneurysms were found in both of those children. Both were still receiving aspirin therapy at the time of the audit, meaning they had been receiving aspirin for over 2 years.

On average the patients stayed in hospital for 5 days, with all of them having been apyrexial for at least 24 hours before discharge. It took 4 days on average between the child being admitted and the diagnosis being made. Treatment always began immediately upon diagnosis.

Eight of the 11 patients were treated with antibiotics during their time in hospital, all prescribed to treat suspected infections. Once KD had been confirmed antibiotics were stopped. One patient received 5 different antibiotics to try and treat a suspected resistant infection. All 11 patients also suffered from irritability during their time in hospital (Table 1).

\section{Discussion}

Kawasaki disease has been shown to be an extremely rare condition. On average only one patient was presented to the hospital every year with KD. In the United States in 2009 about 5,500 cases of KD were diagnosed, while approximately 19,000 patients were diagnosed in Japan in $2008[3,4]$. This shows that KD is more common in Asian populations than in Caucasian with the incidence being 30 cases per 100,000 people in the Asian community, while it is in the region of 16 per 100,000 in the Caucasian population [4]. Fever is a common reason for pediatric admissions, with children expecting to suffer on average from 8 febrile episodes before 18 months of age [5]. This makes $\mathrm{KD}$ even more difficult to diagnose, especially as there is no specific diagnostic test.

A recent study found a possible link between urine proteomics and KD [3]. The proteins Meprin A and filamin C were found to be significantly elevated in those children diagnosed with $\mathrm{KD}$. This could offer new ground in the management of $\mathrm{KD}$; children presenting with KD symptoms could be offered urine testing, possibly leading to quicker and more reliable diagnosis. Our audit found that those who had a fever for a longer period of time suffered more complications. Two of the five patients with a fever lasting for longer than 8 days developed cardiac complications. No children with a fever under 8 days developed complications.

Early urine testing for these proteins in children with a 5-day, unresponsive temperature may help in improving patient outcomes. All of our patients suffered from this type of fever. Our audit found that the average time of fever before diagnosis to be 9 days, with the child suffering one day of fever after treatment had begun, much greater than the 5 of the diagnostic criteria.

Little is known about the etiology if $\mathrm{KD}$. Recent studies have suggested a genetic link, although nothing has been proven yet [6] It has been shown that a sibling of a KD patient is 10-30 times more likely to develop the condition in the future. Parents of KD patients are also twice as likely to have suffered from the disease themselves. These facts do suggest there to be some link between genetics and KD, though more research is required in this area.

Statistics show that $4 \%$ of patients who receive immunoglobulin go on to develop coronary aneurysms $[1,6]$. Of the 2 patients who developed coronary artery aneurysmslreceived immunoglobulin therapy while one did not.

Treatment with aspirin for 6 weeks in combination with immunoglobulin has been found to be most effective in preventing cardiac complications [1,7] and all but one of our patients received this. The one child who did not have high dose aspirin or immunoglobulin treatment went on to develop cardiac aneurysms which highlights the importance of adequate treatment as it is well known that this treatment reduces the risk of cardiac aneurysms from $25 \%$ to $4 \%[1,6,7]$.

The presence of high CRP levels in 10 of the patients also indicates

\begin{tabular}{|c|c|c|c|c|c|c|c|c|c|c|c|c|c|c|}
\hline Patient & $\underset{\begin{array}{c}\text { Age } \\
\text { (months) }\end{array}}{\mid}$ & Sex & Ethnicity & $\begin{array}{l}\text { Weight } \\
(\mathrm{kg})\end{array}$ & $\begin{array}{l}\text { Duration } \\
\text { of fever } \\
\text { (days) }\end{array}$ & $\begin{array}{l}\text { Fever } \\
\text { peak } \\
\left({ }^{\circ} \mathrm{C}\right)\end{array}$ & $\begin{array}{c}\text { Complete KD? } \\
\text { (no. of diagnostic } \\
\text { criteria) }\end{array}$ & $\begin{array}{l}\text { C-reactive } \\
\text { protein } \\
\text { (mg/L) }\end{array}$ & $\begin{array}{c}\mathrm{Hb} \\
\text { (g/dl) }\end{array}$ & $\begin{array}{l}\text { Platelets } \\
\text { (x109/L) }\end{array}$ & $\begin{array}{l}\text { Length of stay in } \\
\text { hospital (days) }\end{array}$ & $\begin{array}{c}\text { Courses of } \\
\text { immunoglobulins } \\
(2 \mathrm{~g} / \mathrm{kg})\end{array}$ & $\begin{array}{l}\text { Length of } \\
\text { aspirin therapy }\end{array}$ & $\begin{array}{l}\text { Coronary artery } \\
\text { aneurysm? }\end{array}$ \\
\hline 1 & 4 & M & Caucasian & 5.6 & 7 & 40.3 & No (3) & 165 & 8.8 & 473 & 7 & 1 & 44 days & No \\
\hline 2 & 10 & M & Caucasian & 9.3 & 8 & 40.0 & Yes (5) & 299 & 11.5 & 395 & 5 & 1 & 59 days & No \\
\hline 3 & 12 & M & Caucasian & 9.4 & 13 & 40.2 & No (3) & 36 & 10.2 & 715 & 7 & 1 & 33 days & No \\
\hline 4 & 29 & $\mathrm{~F}$ & Caucasian & 15.6 & 7 & 39.9 & Yes (5) & 131 & 10.9 & 356 & 3 & 1 & 45 days & No \\
\hline 5 & 33 & M & Caucasian & 13.2 & 9 & 39.9 & Yes (5) & 131 & 10.4 & 522 & 5 & 1 & 39 dayS & No \\
\hline 6 & 39 & $\mathrm{~F}$ & Chinese & 13.6 & 7 & 40.7 & Yes (5) & 274 & 11.0 & 436 & 6 & 1 & 44 days & No \\
\hline 7 & 40 & $\mathrm{M}$ & Caucasian & 15.3 & 10 & 40.5 & Yes (4) & 147 & 11.0 & 209 & 12 & 1 & 42 days & No \\
\hline 8 & 49 & M & Caucasian & 18.4 & 9 & 39.4 & No (2) & 117 & 11.1 & 659 & 7 & 1 & $\begin{array}{l}26 \text { months } \\
\text { (ongoing) }\end{array}$ & $\begin{array}{l}\text { Yes - } 3 \text { left coronary } \\
\text { artery aneurysms }\end{array}$ \\
\hline 9 & 53 & M & Caucasian & 16.6 & 28 & 39.2 & Yes (4) & $<1$ & 11.4 & 340 & 2 (diagnosed later) & 0 & $\begin{array}{l}29 \text { months } \\
\text { (ongoing) }\end{array}$ & $\begin{array}{c}\text { Yes - } 3 \text { left coronary } \\
\text { artery aneurysms }\end{array}$ \\
\hline 10 & 56 & $\mathrm{~F}$ & Caucasian & 14.8 & 6 & 37.9 & Yes (4) & 39 & 11.6 & 711 & 6 & 1 & 42 days & No \\
\hline 11 & 62 & $\mathrm{~F}$ & Caucasian & 18.1 & 7 & 39.5 & Yes (4) & 45 & 11.0 & 245 & 2 & 1 & 15 days & No \\
\hline
\end{tabular}

Table 1: Kawasaki audit table. 
Citation: Davison M, Meridis G, Strehle EM (2013) Ten-year Audit of Kawasaki Disease in a District General Hospital. Human Genet Embryol 3: 106. doi:10.4172/2161-0436.1000106

Page 3 of 3

this is an important factor in diagnosing KD. However, this does come with limitations as CRP is very non-specific and would be raised in a number of acute and chronic conditions [1,2].

The sample size for the audit was small, with only 11 patients being diagnosed over the past 10 years. This creates difficulties in drawing confident conclusions as the data may be unreliable. All the information was gathered from patient notes so any unrecorded data would be impossible to process.

In summary, a retrospective case note audit was performed and found that delay in diagnosis can be an important factor in cardiac complications. The data analyzed highlighted the importance of early diagnosis and adequate treatment to protect against cardiac complications. It is hoped that new genetic testing will help clinicians achieve these goals in the near future.

\section{References}

1. Kliegman R.M. (2011) Nelson Textbook of Pediatrics: 19th Edition, Elsevier/ Saunders.

2. Mclntosh N, Helms PJ, Smyth RL, Logan S (2003) Forfar and Arneil's Textbook of Pediatrics. (7thedn), Churchill Livingstone.

3. Kentsis A, Shulman A, Ahmed S, Brennan E, Monuteaux MC, et al. (2013) Urine proteomics for discovery of improved diagnostic markers of Kawasaki disease. EMBO Mol Med 5: 210-220.

4. Coustasse A, Larry J, Lee D (2012) Can Kawasaki disease be managed? Perm J 16: 70-72.

5. Illsley A (2008) Management of the child with fever: an audit; NICE.

6. Onouchi $Y$ (2012) Genetics of Kawasaki disease: what we know and don't know. Circ J 76: 1581-1586.

7. Tacke CE, Burgner D, Kuipers IM, Kuijpers TW (2012) Management of acute and refractory Kawasaki disease. Expert Rev Anti Infect Ther 10: 1203-1215. 